\title{
Nickel Decorated on Phosphorous-Doped Carbon Nitride as an Efficient Photocatalyst for Reduction of Nitrobenzenes
}

\author{
Anurag Kumar ${ }^{1,2}$, Pawan Kumar ${ }^{1,2,+}$, Chetan Joshi 1, ${ }^{\dagger}$, Manvi Manchanda ${ }^{1}$, \\ Rabah Boukherroub ${ }^{3, *}$ and Suman L. Jain ${ }^{1, *}$ \\ 1 CSIR Indian Institute of Petroleum, Haridwar road Mohkampur, Dehradun 248005, India; \\ anuragmnbd@gmail.com (A.K.); choudhary.2486pawan@yahoo.in (P.K.); chetanjoshi019@gmail.com (C.J.); \\ manvimanchanda@gmail.com (M.M.) \\ 2 Academy of Scientific and Industrial Research (AcSIR), New Delhi 110001, India \\ 3 Institut d'Electronique, de Microélectronique et de Nanotechnologie (IEMN), UMR CNRS 8520, \\ Université Lille1, Avenue Poincaré-BP 60069, 59652 Villeneuve d'Ascq, France \\ * Correspondence: rabah.boukherroub@iemn.univ-lille1.fr (R.B.); suman@iip.res.in (S.L.J.); \\ Tel.: +91-135-2525-788 (S.L.J.); +33-0-3-62-53-17-24 (R.B.); \\ Fax: +91-135-2660-098 (S.L.J.); +33-0-3-62-53-17-01 (R.B.) \\ + These authors contributed equally to this work.
}

Academic Editors: Hermenegildo García and Sergio Navalón Received: 3 February 2016; Accepted: 21 March 2016; Published: 1 April 2016

\begin{abstract}
Nickel nanoparticle-decorated phosphorous-doped graphitic carbon nitride $\left(\mathrm{Ni} @ \mathrm{~g}-\mathrm{PC}_{3} \mathrm{~N}_{4}\right)$ was synthesized and used as an efficient photoactive catalyst for the reduction of various nitrobenzenes under visible light irradiation. Hydrazine monohydrate was used as the source of protons and electrons for the intended reaction. The developed photocatalyst was found to be highly active and afforded excellent product yields under mild experimental conditions. In addition, the photocatalyst could easily be recovered and reused for several runs without any detectable leaching during the reaction.
\end{abstract}

Keywords: carbon nitride; nickel nanoparticles; photocatalysis; visible light; nitrobenzene reduction

\section{Introduction}

Solar energy is abundant, inexpensive and has great potential for use as a clean and economical energy source for organic transformations [1-4]. Thus, the efficient conversion of solar energy to chemical energy, i.e., visible light-driven chemical conversion (photocatalysis) is an area of tremendous importance and has been rapidly growing worldwide during the last two decades. The reduction of nitrobenzenes to the corresponding amines is an important transformation both in organic synthesis as well as in the chemical industry [5-7]. The conventional methods for this reaction mainly require harsh reaction conditions, expensive reagents, multi-step synthetic procedures and mostly generate hazardous waste [8,9]. Owing to the current need to develop greener and sustainable synthesis, the visible light-assisted reduction of nitrobenzenes to the corresponding amines is highly desired, as these reactions occur under mild and ambient conditions [10]. So far, semiconducting materials, mainly $\mathrm{TiO}_{2}$-based heterogeneous photocatalysts, have been widely used for the reduction of nitrobenzenes [11]. However, these photocatalysts work only under ultraviolet (UV) irradiation, which is a small part of the solar spectrum and also needs special reaction vessels. In order to improve their efficiency in the visible region, surface modification of the $\mathrm{TiO}_{2}$ photocatalyst by doping metal or metal oxides, oxide halides (i.e., $\mathrm{PbPnO}_{2} \mathrm{X}(\mathrm{Pn}=\mathrm{Bi}, \mathrm{Sb} ; \mathrm{X}=\mathrm{Br}, \mathrm{Cl}$ ) and sensitization with dyes has also been demonstrated [12-14]. However, the tedious synthetic procedures and poor product yields limit the synthetic utility of these methods. 
Another semiconducting material, i.e., carbon nitride, has gained significant attention in recent years due to its low band gap (2.7 eV) and easy synthesis method [15-17]. The graphitic carbon nitride $\left(\mathrm{g}-\mathrm{C}_{3} \mathrm{~N}_{4}\right)$ is a two dimensional (2D) polymer consisting of interconnected tri-s-triazine units via tertiary amines. The low band gap and the appropriate position of the conduction $(-1.1 \mathrm{eV})$ and valence $(+1.6 \mathrm{eV})$ bands enable it to initiate any redox reaction [18]. Despite of several advantages, it also suffers from certain drawbacks such as only being able to absorb blue light up to the $450 \mathrm{~nm}$ wavelength, so the red region of visible light cannot be harvested. In order to widen the absorption profile in the whole visible region, the doping of elements such as phosphorus $(\mathrm{P})$, boron $(\mathrm{B})$, fluorine $(\mathrm{F})$, etc is important because these atoms form bonds with nitrogen and contribute their electrons to the $\pi$-conjugated system more efficiently. Recently, Zhang et al. synthesized P-doped $g-\mathrm{C}_{3} \mathrm{~N}_{4}$ with an improved photocurrent response by using 1-butyl-3-methylimidazolium hexafluorophosphate $\left(\mathrm{BmimPF}_{6}\right)$ as a source of phosphorous [19]. Hong and coworkers synthesized sulfur-doped mesoporous carbon nitride (mpgCNS) using an in situ doping method, which showed increased photocatalytic performance for the solar hydrogen production [20]. Wang et al. synthesized fluorine-doped carbon nitride by using ammonium fluoride as a cheap source of fluorine for the enhanced visible light-driven hydrogen evolution reaction [21]. Very recently, our group reported an iron(II) bipyridine complex grafted nanoporous carbon nitride $\left(\mathrm{Fe}(\mathrm{bpy})_{3} / \mathrm{npg}-\mathrm{C}_{3} \mathrm{~N}_{4}\right)$ photocatalyst for the visible light-mediated oxidative coupling of benzylamines to imines [22].

In continuation of our ongoing research on the development of novel photocatalysts [23-25], herein we report for the first time on nickel nanoparticles grafted on P-doped g- $\mathrm{C}_{3} \mathrm{~N}_{4}\left(\mathrm{Ni} @ g-\mathrm{PC} \mathrm{N}_{4}\right)$ as a high-performance photocatalyst for the reduction of nitrobenzenes to the corresponding amines at ambient temperature under visible light irradiation (Scheme 1). Due to better visible light absorption, P-doped carbon nitride can generate electron-hole pairs under visible light irradiation, while nickel nanoparticles, due to their lower Fermi level than conduction band of $\mathrm{P}-\mathrm{C}_{3} \mathrm{~N}_{4}$, can work as electron capturing agents to slow down the process of electron-hole recombination and enhance the catalytic activity and reaction rate.

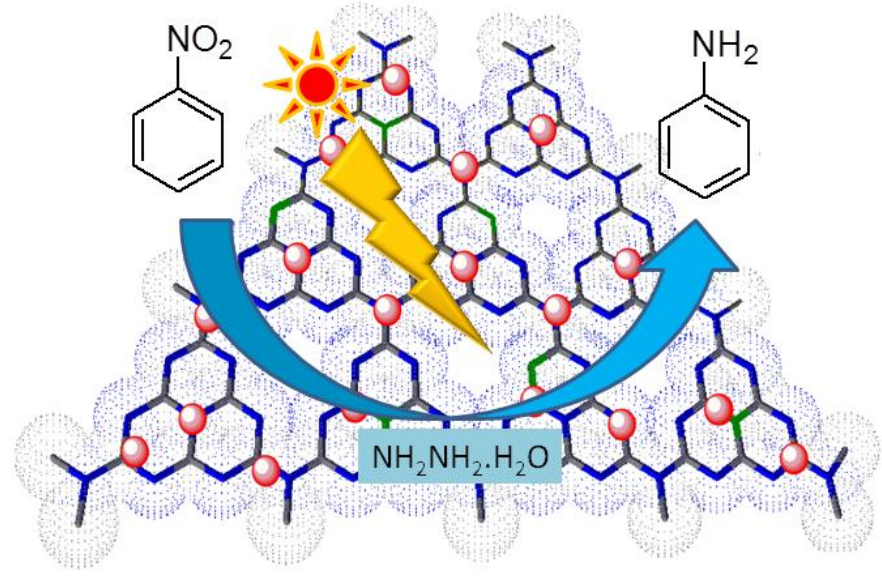

Scheme 1. Reduction of nitrobenzenes on Ni@g- $\mathrm{PC}_{3} \mathrm{~N}_{4}$ (nickel nanoparticles grafted on P-doped $\mathrm{g}-\mathrm{C}_{3} \mathrm{~N}_{4}$ ) catalyst.

\section{Results and Discussion}

\subsection{Synthesis and Characterization of the Photocatalyst}

At first, nickel nanoparticles were synthesized by reducing nickel chloride hexahydrate by sodium borohydride in the presence of cetyltrimethylammonium bromide (CTAB) as a template by following the literature procedure in [26]. Next, the synthesis of phosphorous-doped graphitic carbon nitride $\left(\mathrm{g}-\mathrm{PC}_{3} \mathrm{~N}_{4}\right.$ ) was performed by using ionic liquid 1-butyl-3-methylimidazolium hexafluorophosphate 
$\left[\mathrm{BmimPF}_{6}\right]$ as a source of phosphorous and dicyandiamide as a precursor for the graphitic carbon nitride skeleton $[17,27]$. Nickel nanoparticle-decorated phosphorous-doped carbon nitride $\left(\mathrm{Ni@g}-\mathrm{PC}_{3} \mathrm{~N}_{4}\right)$ with variable nickel content $(2-7.5 \mathrm{wt} \%)$ was synthesized by the addition of nickel nanoparticles, $\mathrm{BmimPF}_{6}$ and dicyandiamide into water with continuous stirring. The resulting suspension was heated at $100{ }^{\circ} \mathrm{C}$ until all the water was evaporated. Then, the obtained solid was heated at a programmed temperature in a similar manner to the one used for P-doped carbon nitride (Scheme 2). Bare graphitic carbon nitride $\left(\mathrm{g}-\mathrm{C}_{3} \mathrm{~N}_{4}\right)$ was synthesized for comparison by heating dicyandiamide under identical programmed temperature. Among the various nanocomposites synthesized, $5 \%$ nickel nanoparticles grafted on P-doped g- $\mathrm{C}_{3} \mathrm{~N}_{4}\left(5 \% \mathrm{Ni} @ \mathrm{PC}_{3} \mathrm{~N}_{4}\right)$ exhibited the best performance for the photocatalytic reduction of nitrobenzene; thus, we have used this photocatalyst for detailed characterization and further studies.

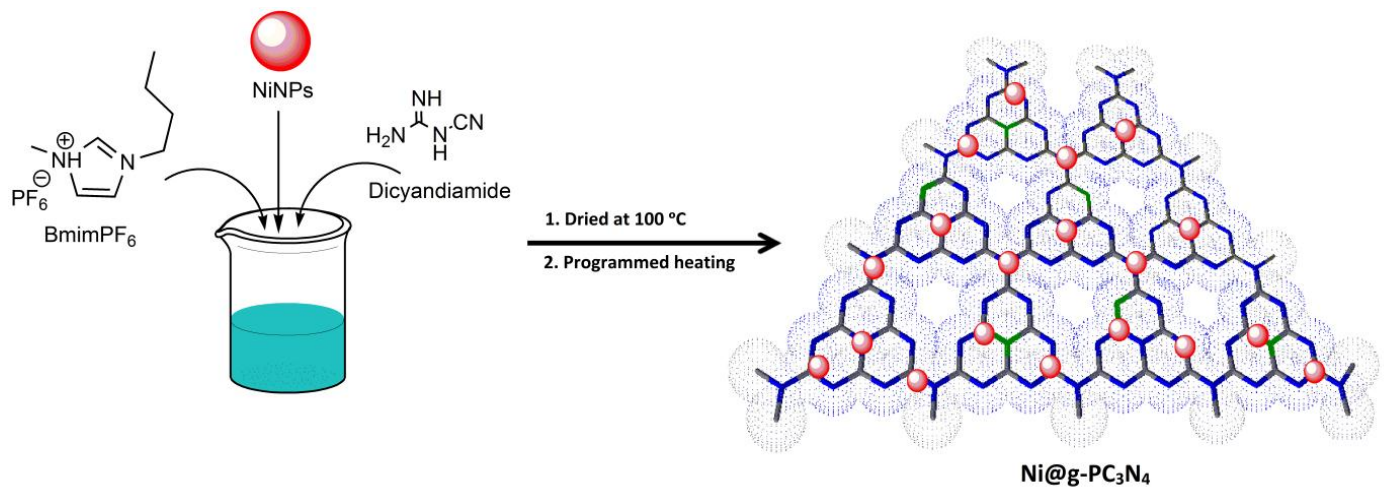

Scheme 2. Synthetic illustration of $\mathrm{Ni@g}-\mathrm{PC}_{3} \mathrm{~N}_{4}$ catalyst. NiNPs: nickel nanoparticles; $\mathrm{BmimPF}_{6}$ : 1-butyl-3-methylimidazolium hexafluorophosphate.

The surface morphology of the synthesized materials was determined by field emission scanning electron microscopy (FE-SEM). The graphitic carbon nitride $\left(\mathrm{g}-\mathrm{C}_{3} \mathrm{~N}_{4}\right)$ showed many enfolded and crumpled sheet-like structures (Figure 1a). The framework of $C_{3} N_{4}$ contains nitrogen as a substituted heteroatom forming similarly to the $\pi$-conjugated system, as in graphitic planes, due to $\mathrm{sp}^{2}$ hybridization between carbon and nitrogen atoms. The phosphorous-doped carbon nitride $\left(\mathrm{g}-\mathrm{PC}_{3} \mathrm{~N}_{4}\right.$ ) exhibits similar morphological characteristics (Figure 1b). In the case of nickel nanoparticle-grafted g- $-\mathrm{PC}_{3} \mathrm{~N}_{4}\left(5 \% \mathrm{Ni} @ g-\mathrm{PC}_{3} \mathrm{~N}_{4}\right)$, a similar sheet-like morphology was observed that may be due to the incorporation of nickel nanoparticles between the graphitic carbon nitride sheets (Figure 1c). The energy dispersive $\mathrm{X}$-ray spectroscopy (EDX) pattern of g- $\mathrm{PC}_{3} \mathrm{~N}_{4}$ clearly showed the presence of phosphorous (Figure 1e) and, in $5 \% \mathrm{Ni@g}-\mathrm{PC}_{3} \mathrm{~N}_{4}$, the peak due to nickel can clearly be seen, which confirmed the presence of both components in the synthesized photocatalyst (Figure 1f).

The fine morphological features of the synthesized materials were determined with the help of high-resolution transmission electron microscopy (HRTEM). The transmission electron microscopy (TEM) image of g- $\mathrm{C}_{3} \mathrm{~N}_{4}$ at $100 \mathrm{~nm}$ resolution displayed enfolded sheets of carbon nitride (Figure 2a). For g- $\mathrm{PC}_{3} \mathrm{~N}_{4}$, similar folded sheet-like structures were observed, indicating that phosphorus doping did not change the structural features of the material (Figure 2b). In the TEM image of $5 \% \mathrm{Ni@g}-\mathrm{PC}_{3} \mathrm{~N}_{4}$, several small dark spots were observed, suggesting the presence of nickel nanoparticles between the scaffolds of graphitic structure of phosphorous-doped carbon nitride (Figure 2c). The presence of several rings and bright spots in the selected area electron diffraction (SAED) pattern of $5 \% \mathrm{Ni} @ \mathrm{~g}-\mathrm{PC}_{3} \mathrm{~N}_{4}$ confirmed the presence of nickel nanoparticles in the composite structure (Figure 2d). Further EDX patterns of $5 \% \mathrm{Ni@g}-\mathrm{PC}_{3} \mathrm{~N}_{4}$ revealed the presence of all the expected elements in the photocatalyst (Figure 2e). 

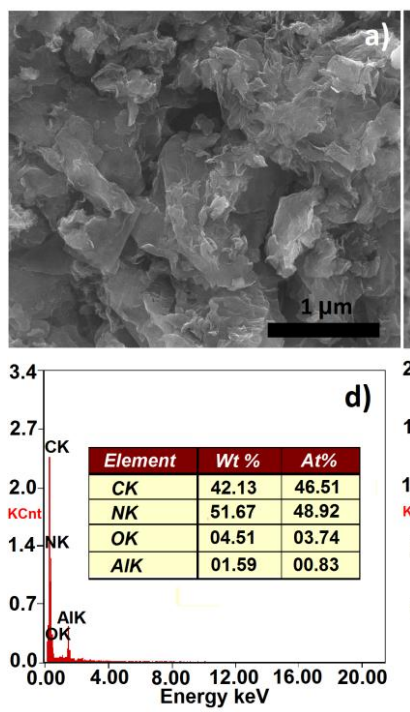
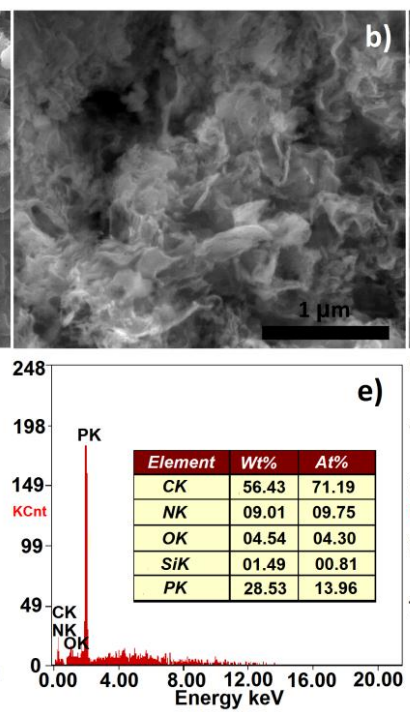

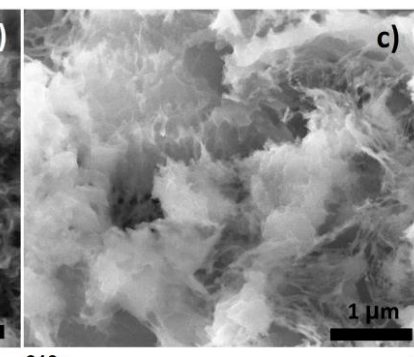

(3)

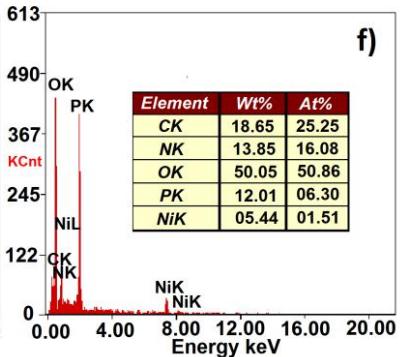

Figure 1. Field emission scanning electron microscopy (FE-SEM) image of: (a) graphitic carbon nitride $\left(\mathrm{g}-\mathrm{C}_{3} \mathrm{~N}_{4}\right)$; (b) phosphorous-doped graphitic carbon nitride $\left(\mathrm{g}-\mathrm{PC}_{3} \mathrm{~N}_{4}\right)$; (c) nickel nanoparticle-grafted g- $\mathrm{PC}_{3} \mathrm{~N}_{4}\left(\mathrm{Ni@g}-\mathrm{PC}_{3} \mathrm{~N}_{4}\right)$; energy dispersive X-ray spectroscopy (EDX) pattern of: (d) $\mathrm{g}-\mathrm{C}_{3} \mathrm{~N}_{4}$; (e) $\mathrm{g}-\mathrm{PC}_{3} \mathrm{~N}_{4} ;$ (f) $5 \% \mathrm{Ni} @ g-\mathrm{PC}_{3} \mathrm{~N}_{4}$.

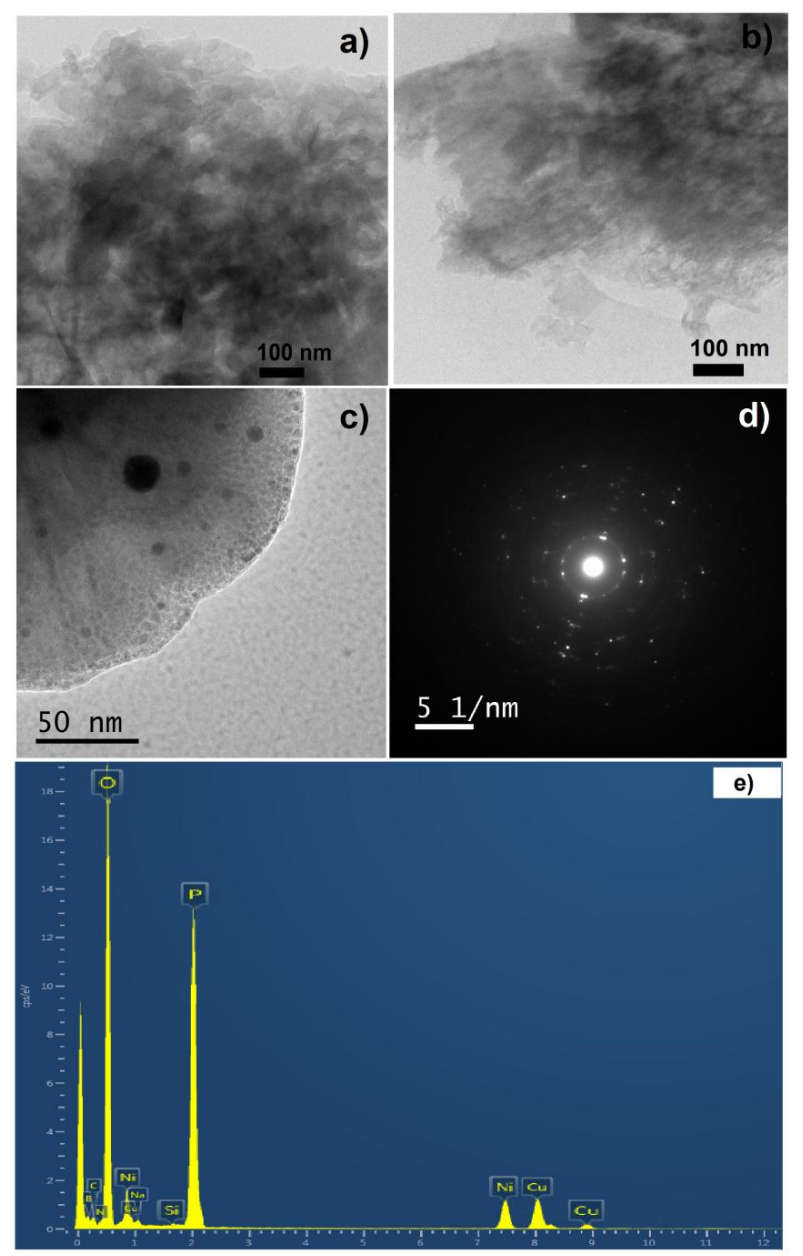

Figure 2. Transmission electron microscopy (TEM) images of: (a) $\mathrm{g}-\mathrm{C}_{3} \mathrm{~N}_{4} ;(\mathbf{b}) \mathrm{g}-\mathrm{PC}_{3} \mathrm{~N}_{4} ;(\mathbf{c}) \mathrm{Ni} g \mathrm{~g}-\mathrm{PC}_{3} \mathrm{~N}_{4}$; (d) selected area electron diffraction (SAED) pattern of $\mathrm{Ni@g}-\mathrm{PC}_{3} \mathrm{~N}_{4} ;(\mathbf{e})$ EDX pattern of $\mathrm{Ni} @ \mathrm{~g}-\mathrm{PC}_{3} \mathrm{~N}_{4}$. 
The vibrational spectra of the synthesized materials are depicted in Figure 3. The Fourier transform infrared (FTIR) spectrum of as-synthesized nickel nanoparticles by using cetyl trimethylammonium chloride as a template was found to be well in agreement with the known literature and gave peaks at $676 \mathrm{~cm}^{-1}$ due to the $\mathrm{Ni}-\mathrm{O}$ stretch of oxidized nickel [28]. Some additional peaks were also identified that may be due to the residual template molecules in the particles. The FTIR spectrum of carbon nitride $\left(\mathrm{g}-\mathrm{C}_{3} \mathrm{~N}_{4}\right)$ showed a characteristic peak at $815 \mathrm{~cm}^{-1}$ related to $\mathrm{C}-\mathrm{N}$ heterocycles due to the triazine ring mode. Another peak in the range of $1200-1600 \mathrm{~cm}^{-1}$, attributed to the specific aromatic skeleton vibration of carbon nitride, was observed [29]. A broad band was evident in the range of $3000-3700 \mathrm{~cm}^{-1}$ corresponding to adsorbed moisture, i.e., the presence of water molecules, or due to the stretching mode of $-\mathrm{NH}_{2}$, which are uncondensed amine groups, or to $\mathrm{N}-\mathrm{H}$ group vibrations present at the surface of carbon nitride (Figure 3a). For the P-doped carbon nitride $\left(\mathrm{g}-\mathrm{PC}_{3} \mathrm{~N}_{4}\right)$, peaks related to $\mathrm{C}-\mathrm{N}$ at 1520,1440 and $1310 \mathrm{~cm}^{-1}$ were found to be diminished, which is mainly due to the displacement of some carbon atoms in the ring skeleton by the phosphorous atoms to give $\mathrm{P}-\mathrm{N}$ bonds. Furthermore, a new peak at $980 \mathrm{~cm}^{-1}$ due to the vibration of the C-P heterocycle was clearly observed (Figure 3c). For the $5 \% \mathrm{Ni@g-PC} \mathrm{N}_{4}$, the appearance of some peaks due to nickel nanoparticles with g- $\mathrm{PC}_{3} \mathrm{~N}_{4}$ confirmed the successful synthesis of nickel-grafted P-doped g- $\mathrm{C}_{3} \mathrm{~N}_{4}$ (Figure $3 \mathrm{~d}$ ).

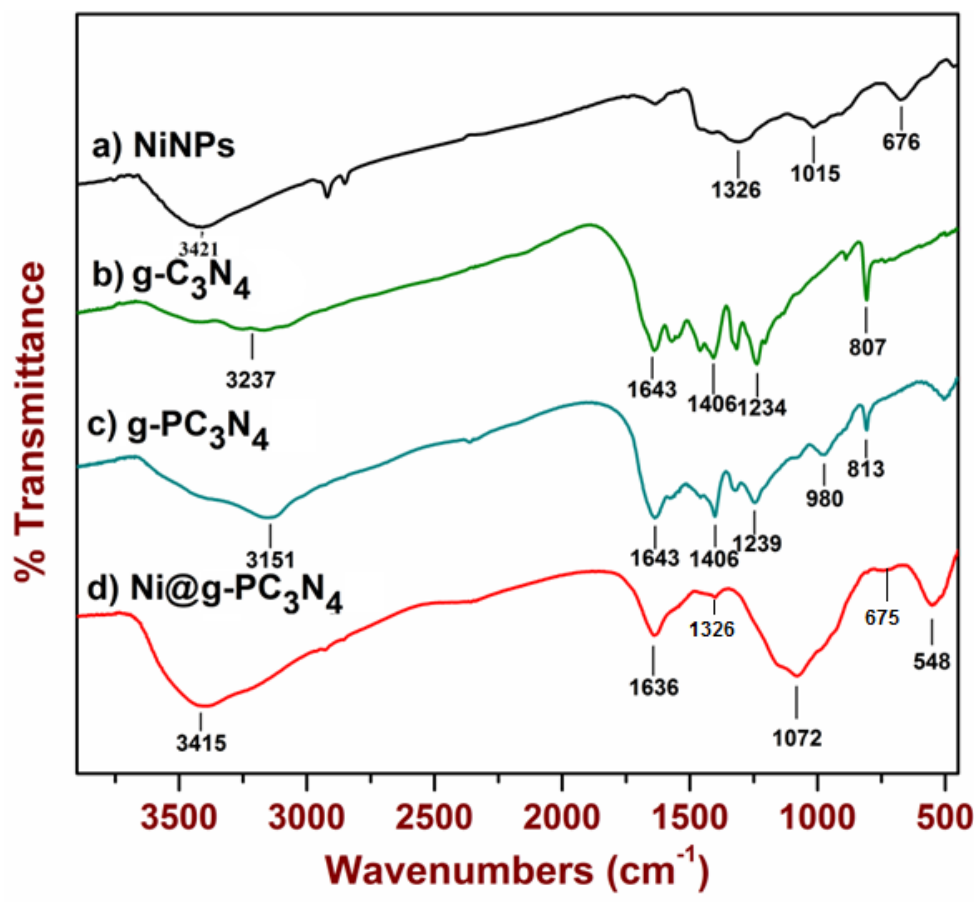

Figure 3. Fourier transform infrared (FTIR) spectra of: (a) nickel nanoparticles (NiNPs); (b) g- $\mathrm{C}_{3} \mathrm{~N}_{4}$;

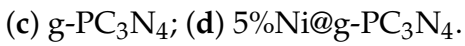

The crystallinity and phase structure of the nanocomposites were determined by $\mathrm{X}$-ray diffraction (XRD) (Figure 4). The XRD diffraction pattern of graphitic carbon nitride $\left(\mathrm{g}-\mathrm{C}_{3} \mathrm{~N}_{4}\right)$ revealed an intense broad peak at the $2 \theta$ value of $27.4^{\circ}$, indexed to (002) planes with $0.32 \mathrm{~nm}$ interlayer distance due to the stacking of graphite-like conjugated triazine aromatic sheets, which matches well with Joint committee on powder diffraction standards (JCPDS) 87-1526 for g- $\mathrm{C}_{3} \mathrm{~N}_{4}$ (Figure 4a) [30]. The g- $\mathrm{PC}_{3} \mathrm{~N}_{4}$ also exhibited an identical diffraction pattern; however, the intensity of the peak at $27.4^{\circ}$ was found to be reduced due to the replacement of carbon atoms by phosphorous atoms (Figure $4 \mathrm{~b}$ ). The diffraction pattern of the $5 \% \mathrm{Ni} @ g-\mathrm{PC}_{3} \mathrm{~N}_{4}$ did not show any peak of nickel nanoparticles. This is most likely due to the amorphous nature of the material (Figure 4c). Furthermore, the peak at $27.4^{\circ}$ was absent in $5 \% \mathrm{Ni} @ g-\mathrm{PC}_{3} \mathrm{~N}_{4}$, which was most probably due to the intercalation of nickel nanoparticles between the 
sheets. Therefore, the interlayer distance between sheets increased and the diffraction due to stacked sheets disappeared.

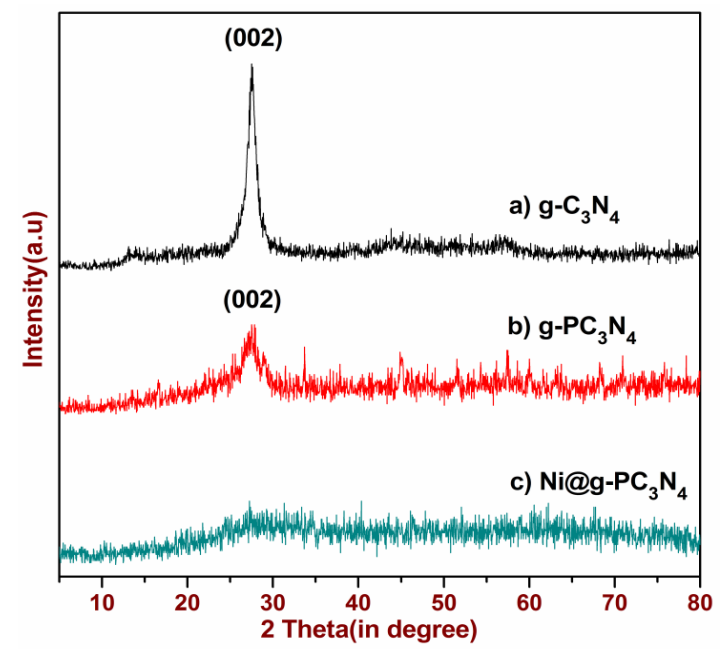

Figure 4. X-ray diffraction (XRD) patterns of: (a) $\mathrm{g}-\mathrm{C}_{3} \mathrm{~N}_{4}$; (b) $\mathrm{g}-\mathrm{PC}_{3} \mathrm{~N}_{4}$; (c) $5 \% \mathrm{Ni} @ \mathrm{~g}-\mathrm{PC}_{3} \mathrm{~N}_{4}$. a.u.: arbitrary units.

To determine the surface properties of the synthesized materials, $\mathrm{N}_{2}$ adsorption-desorption isotherms were determined by using multilayer Brunauer-Emmett-Teller (BET) adsorption-desorption theory. As seen in Figure 5, the adsorption-desorption isotherms were of type IV, suggesting the mesoporous nature of the materials [31]. The BET surface area $\left(S_{\mathrm{BET}}\right)$, total pore volume $\left(V_{\mathrm{p}}\right)$ and mean pore diameter $\left(r_{\mathrm{p}}\right)$ of $\mathrm{g}-\mathrm{C}_{3} \mathrm{~N}_{4}$ were found to be $14.67 \mathrm{~m}^{2} \cdot \mathrm{g}^{-1}, 0.15 \mathrm{~cm}^{3} \cdot \mathrm{g}^{-1}$ and $4.21 \mathrm{~nm}$, while for $\mathrm{g}-\mathrm{PC}_{3} \mathrm{~N}_{4}$ these values were determined to be $24.59 \mathrm{~m}^{2} \cdot \mathrm{g}^{-1}, 0.14 \mathrm{~cm}^{3} \cdot \mathrm{g}^{-1}$ and $3.83 \mathrm{~nm}$, respectively. For the $5 \% \mathrm{Ni} @ \mathrm{~g}-\mathrm{PC}_{3} \mathrm{~N}_{4}$ surface area $\left(S_{\mathrm{BET}}\right)$, the total pore volume $\left(V_{\mathrm{p}}\right)$ and mean pore diameter $\left(r_{\mathrm{p}}\right)$ were $48.62 \mathrm{~m}^{2} \cdot \mathrm{g}^{-1}, 0.17 \mathrm{~cm}^{3} \cdot \mathrm{g}^{-1}$ and $2.64 \mathrm{~nm}$, respectively. The change in the surface properties clearly indicated the grafting of nickel nanoparticles between the sheets of carbon nitride (Figure 5). The higher surface area provides more sites for reaction to proceed on the surface of the $\mathrm{Ni} g \mathrm{~g}-\mathrm{PC}_{3} \mathrm{~N}_{4}$ catalyst.

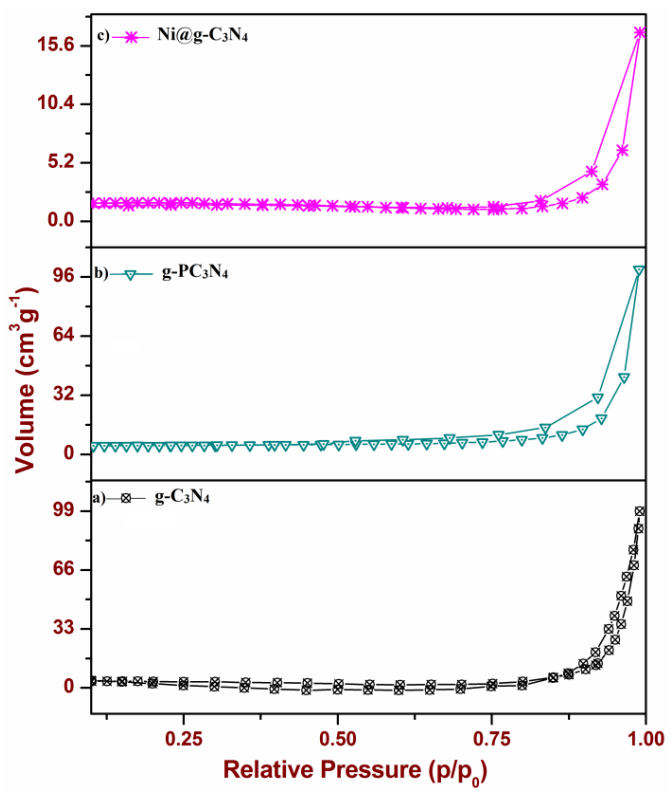

Figure 5. $\mathrm{N}_{2}$ adsorption-desorption isotherm and pore size distribution of: (a) $\mathrm{g}-\mathrm{C}_{3} \mathrm{~N}_{4} ;(\mathbf{b}) \mathrm{g}-\mathrm{PC}_{3} \mathrm{~N}_{4}$; (c) $5 \% \mathrm{Ni} @ g-\mathrm{PC}_{3} \mathrm{~N}_{4}$. 
Electronic and optical properties are of fundamental importance to determine the photo activity of a catalyst. The absorption properties of synthesized materials were determined by UV-visible (UV-Vis) spectroscopy. The UV-visible spectrum of pure $\mathrm{g}-\mathrm{C}_{3} \mathrm{~N}_{4}$ shows an absorption spectrum similar to a typical semiconductor absorption spectrum between $200-450 \mathrm{~nm}$, originating from the charge transfer from a populated valence band of nitrogen atom ( $2 p$ orbitals) to a conduction band of carbon atom ( $2 \mathrm{p}$ orbitals) of carbon nitride [32]. An additional sharp peak at $256 \mathrm{~nm}$, attributed to the aromatic

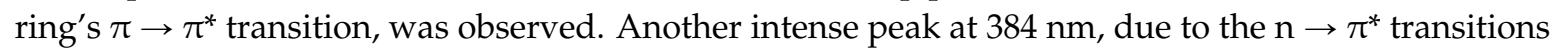
caused by the electron transfer from a nitrogen nonbonding orbital to an aromatic anti-bonding orbital, was also present in the UV-Vis spectrum. The band tailing from 410 to $500 \mathrm{~nm}$ suggests a slight visible light absorption capacity of carbon nitride (Figure 6a). After doping with phosphorous atoms, the absorption band due to the nitrogen nonbonding to aromatic antibonding $\left(\mathrm{n} \rightarrow \pi^{*}\right)$ transition was diminished due to the replacement of carbon atoms with phosphorous, whereas the absorption pattern was found to be redshifted due to the better charge contribution by loosely bound electrons of phosphorous in the aromatic conjugated system (Figure 6b) [33]. After incorporation of nickel nanoparticles $\left(5 \% \mathrm{Ni} @ \mathrm{~g}-\mathrm{PC}_{3} \mathrm{~N}_{4}\right)$, the material exhibited lower absorbance in the visible region as the nickel nanoparticles have lower absorbance in the visible region, and therefore reduce the absorption profile in the visible region (Figure 6c).

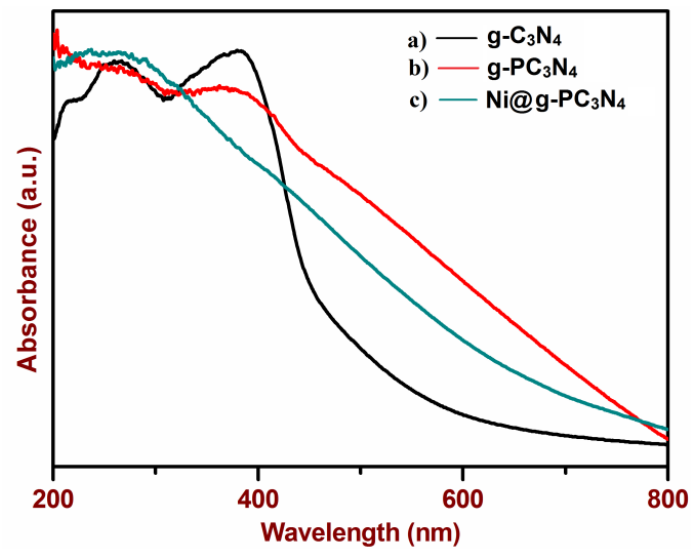

Figure 6. Ultraviolet-visible (UV-Vis) absorption spectra of: (a) $\mathrm{g}_{-} \mathrm{C}_{3} \mathrm{~N}_{4}$; (b) $\mathrm{g}-\mathrm{PC}_{3} \mathrm{~N}_{4}$; (c) $5 \% \mathrm{Ni} @ \mathrm{~g}-\mathrm{PC}_{3} \mathrm{~N}_{4}$.

In order to confirm the visible light absorption of the synthesized photocatalysts, a Tauc plot was obtained as shown in Figure 7. From the Tauc plot, the band gap value for the $g-C_{3} N_{4}$ was determined to be $2.69 \mathrm{eV}$ due to the uneven synthesis of sheets, and was well in concordance with the existing literature [18]. After doping with phosphorous atoms $\left(\mathrm{g}-\mathrm{PC}_{3} \mathrm{~N}_{4}\right)$, the value of the band gap decreased to $1.45 \mathrm{eV}$, which may be due to the displacement of carbon atoms by the phosphorous atoms in the triazine ring skeletons of carbon nitride. For the $5 \% \mathrm{Ni} @ \mathrm{~g}-\mathrm{PC}_{3} \mathrm{~N}_{4}$, a band gap value of $1.52 \mathrm{eV}$ was calculated, which is nearly similar to that of $\mathrm{g}-\mathrm{PC}_{3} \mathrm{~N}_{4}$.

The thermal stability of the synthesized materials was examined by thermogravimetric analysis (Figure 8). A thermogravimetric analysis (TGA) pattern of pristine nickel nanoparticles showed steady weight loss (approx. 15\%) from 100 to $500{ }^{\circ} \mathrm{C}$, which may be due to loss of the residual organic template $(\mathrm{CTAB})$ and loss of other oxygen-carrying functionalities during the crystallization step (Figure 8a). The thermogram of $\mathrm{g}-\mathrm{C}_{3} \mathrm{~N}_{4}$ exhibited a sharp weight loss in the range of 560 to $720^{\circ} \mathrm{C}$ (Figure $8 \mathrm{~b}$ ). The P-doped $\mathrm{g}-\mathrm{C}_{3} \mathrm{~N}_{4}$ displayed a similar weight loss pattern as $\mathrm{g}-\mathrm{C}_{3} \mathrm{~N}_{4}$ (Figure $8 \mathrm{c}$ ). For the $5 \% \mathrm{Ni} @ \mathrm{~g}-\mathrm{PC}_{3} \mathrm{~N}_{4}$, a small weight loss at around $100{ }^{\circ} \mathrm{C}$ was observed due to the loss of moisture, followed by steady weight loss up to $700{ }^{\circ} \mathrm{C}$ due to the loss of template in nickel and the slow degradation of the phosphorous-doped sheets. At $770^{\circ} \mathrm{C}$, a sharp weight loss was observed due to the complete degradation of P-doped carbon nitride sheets (Figure 8d). 


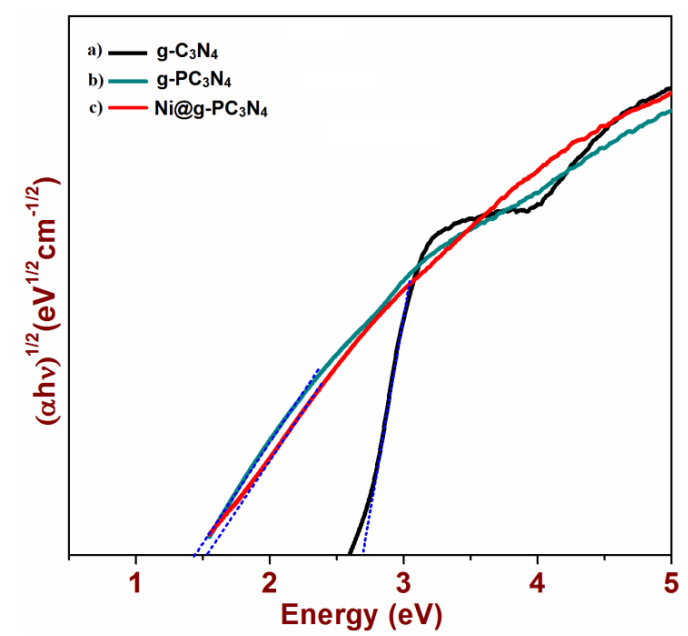

Figure 7. Tauc plots of (a) g- $\mathrm{C}_{3} \mathrm{~N}_{4} ;$ (b) g- $\mathrm{PC}_{3} \mathrm{~N}_{4}$; (c) Ni@g- $\mathrm{PC}_{3} \mathrm{~N}_{4}$. $\alpha$ : absoption coefficient; hv: energy of incident photon.
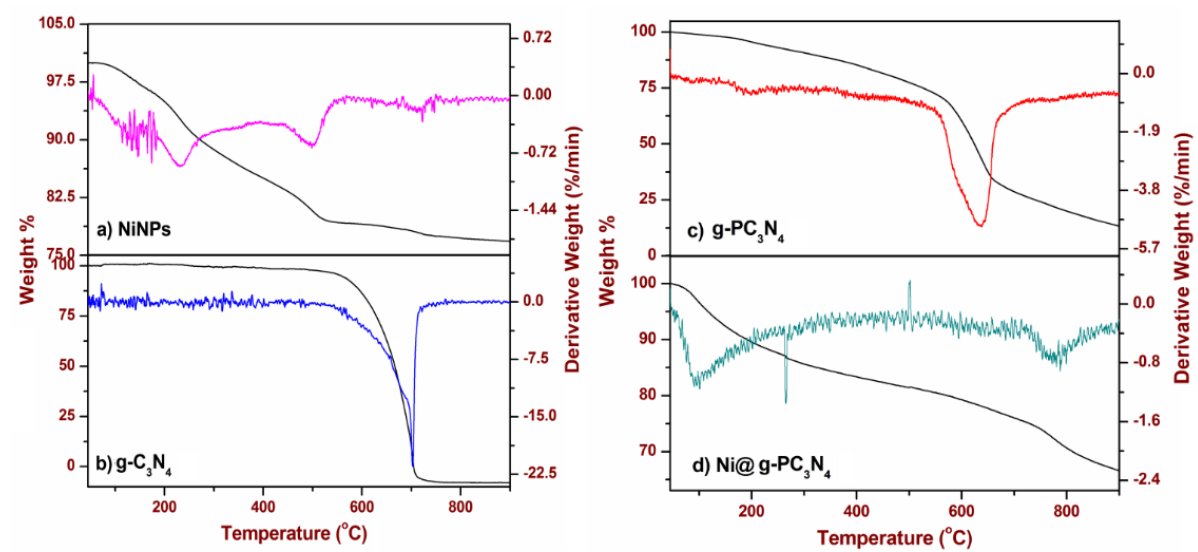

Figure 8. Thermogravimetric analysis (TGA) spectra of: (a) NiNPs; (b) $g-\mathrm{C}_{3} \mathrm{~N}_{4}$; (c) g- $\mathrm{PC}_{3} \mathrm{~N}_{4}$; (d) $5 \% \mathrm{Ni} @ \mathrm{~g}-\mathrm{PC}_{3} \mathrm{~N}_{4}$.

\subsection{Photocatalytic Reduction Reaction}

The photocatalytic activity of the synthesized NiNPs, g- $\mathrm{C}_{3} \mathrm{~N}_{4}$, g- $-\mathrm{PC}_{3} \mathrm{~N}_{4}$ and 2-7.5\%Ni@g- $\mathrm{PC}_{3} \mathrm{~N}_{4}$ catalysts was tested for the reduction of nitrobenzene as a model substrate using hydrazine monohydrate as a proton source under visible light irradiation. The results of these optimization experiments are summarized in Table 1 . There was no conversion obtained with pristine nickel nanoparticles (NiNPs) (Table 1, entry 1). However, the yield of product was found to be $24.6 \%$ when g- $\mathrm{C}_{3} \mathrm{~N}_{4}$ was used as a photocatalyst (Table 1, entry 2). In case of P-doped g- $\mathrm{PC}_{3} \mathrm{~N}_{4}$, the yield of aniline increased up to $54.2 \%$, which clearly indicated the promoting effect of P-doping due to the better visible light absorption (Table 1, entry 3). Furthermore, the yield of aniline increased to manifold by using $\mathrm{Ni@g-PC} \mathrm{P}_{3}$ and, after $8 \mathrm{~h}$ of visible light irradiation, the yield reached $96.5 \%$ (Table 1 , entries 4-6). This increase in the reaction rate and product yield can be explained because the nickel nanoparticles work as electron sinks, and the photogenerated electrons flow from conduction band of $\mathrm{g}-\mathrm{PC}_{3} \mathrm{~N}_{4}$ to nickel nanoparticles. This makes the electron unavailable for the recombination and therefore increases the activity of the catalyst. We also determined the optimum nickel content in the photocatalyst. It was found that among all the synthesized $\mathrm{Ni@g}-\mathrm{PC}_{3} \mathrm{~N}_{4}$ nanocomposites having variable nickel contents $(2-7.5 \mathrm{wt} \% \mathrm{Ni})$, the nanocomposite having $5 \mathrm{wt} \%$ nickel nanoparticles was the most active and afforded maximum product yield (Table 1 , entry 5 ). In the case of $2 \% \mathrm{Ni}$, the yield of product was lower, whereas no significant enhancement was observed with increasing the 
concentration of $\mathrm{Ni}$ beyond $5 \%$ (Table 1, entry 6). Furthermore, the reaction did not take place in dark conditions at ambient temperature by using g- $\mathrm{C}_{3} \mathrm{~N}_{4}, \mathrm{~g}-\mathrm{PC}_{3} \mathrm{~N}_{4}$ and $\mathrm{Ni} @ \mathrm{~g}-\mathrm{PC}_{3} \mathrm{~N}_{4}$ photocatalysts, which clearly revealed that the reaction was visible light promoted (Table 1). The use of hydrazine hydrate was found to be essential as it provided required protons and no product was formed in the absence of hydrazine hydrate (Table 1, entry 5).

Table 1. Results of optimization experiments ${ }^{a}$. NiNPs: nickel nanoparticles; $g-\mathrm{C}_{3} \mathrm{~N}_{4}$ : graphitic carbon nitride; g- $\mathrm{PC}_{3} \mathrm{~N}_{4}$ : phosphorous doped g- $\mathrm{C}_{3} \mathrm{~N}_{4} ; \mathrm{Ni}$ g- $-\mathrm{PC}_{3} \mathrm{~N}_{4}$ : nickel nanoparticles grafted on P-doped g- $\mathrm{C}_{3} \mathrm{~N}_{4}$; TOF: turn over frequency.

\begin{tabular}{|c|c|c|c|c|c|}
\hline Entry & Catalyst & Conditions & Time (h) & AnilineYield (\%) ${ }^{b}$ & TOF $\left(h^{-1}\right)$ \\
\hline \multirow{2}{*}{1} & \multirow{2}{*}{ NiNPs } & Dark & 24 & - & - \\
\hline & & Visible light & - & - & - \\
\hline \multirow{2}{*}{2} & \multirow{2}{*}{$\mathrm{g}-\mathrm{C}_{3} \mathrm{~N}_{4}$} & Dark & 24 & - & - \\
\hline & & Visible light & 12 & 24.6 & 2.0 \\
\hline \multirow{2}{*}{3} & \multirow{2}{*}{ g-P-C ${ }_{3} \mathrm{~N}_{4}$} & Dark & 24 & - & - \\
\hline & & Visible light & 12 & 54.2 & 4.5 \\
\hline \multirow{2}{*}{4} & \multirow{2}{*}{$2 \% \mathrm{Ni@g}-\mathrm{PC}_{3} \mathrm{~N}_{4}$} & Dark & 24 & - & - \\
\hline & & Visible light & 8 & 82.0 & 10.2 \\
\hline \multirow{3}{*}{5} & \multirow{3}{*}{$5 \% \mathrm{Ni@g-PC} \mathrm{N}_{4}$} & Dark & 24 & Trace & - \\
\hline & & Visible light & 8 & 96.5 & 12.1 \\
\hline & & Visible light & $24^{c}$ & $-c$ & $-c$ \\
\hline \multirow{2}{*}{6} & \multirow{2}{*}{$7.5 \% \mathrm{Ni} @ \mathrm{~g}-\mathrm{PC}_{3} \mathrm{~N}_{4}$} & Dark & 24 & 10 & 0.4 \\
\hline & & Visible light & 8 & 97.0 & 12.1 \\
\hline
\end{tabular}

a Reaction conditions: nitrobenzene, $0.1 \mathrm{mmol}$; catalyst, $25 \mathrm{mg}$; hydrazine monohydrate, $1 \mathrm{mmol}$; Irradiation, White cold $20 \mathrm{~W}$ light emitting diode (LED) $\lambda>400 \mathrm{~nm}$, Power at reaction vessel $70 \mathrm{~W} / \mathrm{m}^{2}$; ${ }^{\mathrm{b}}$ Isolated yield;

${ }^{\mathrm{c}}$ without hydrazine monohydrate.

Based on these optimization experiments, $5 \% \mathrm{Ni} @ g-\mathrm{PC}_{3} \mathrm{~N}_{4}$ was selected as the optimum catalyst for further studies. The reaction was further generalized for various substituted nitrobenzenes and the results are summarized in Table 2. It can be seen that the substituent effect did not play much of a role and excellent product yields were obtained in all cases within 8 to $10.5 \mathrm{~h}$.

Table 2. 5\%Ni@g- $\mathrm{PC}_{3} \mathrm{~N}_{4}$ catalyzed photoreduction of nitrobenzenes ${ }^{\mathrm{a}}$.

\begin{tabular}{|c|c|c|c|c|c|c|}
\hline Entry & Reactant & Product & Time/h & Conversion (\%) $b$ & Yield (\%) ${ }^{c}$ & TOF $\left(h^{-1}\right)$ \\
\hline 1 & & & 8.0 & 98.0 & 96.5 & 12.1 \\
\hline 2 & & & 8.0 & 95.5 & 94.2 & 11.7 \\
\hline 3 & & & 8.0 & 96.4 & 95.4 & 11.9 \\
\hline 4 & & & 8.0 & 94.8 & 93.0 & 11.6 \\
\hline 5 & & & 8.0 & 95.6 & 94.2 & 11.7 \\
\hline 6 & & & 8.0 & 96.0 & 94.6 & 11.8 \\
\hline 7 & & & 8.5 & 90.5 & 89.4 & 10.5 \\
\hline 8 & & & 8.5 & 92.4 & 91.0 & 10.7 \\
\hline 9 & & & 10.5 & 93.6 & 92.8 & 8.8 \\
\hline 10 & & & 10.5 & 90.4 & 89.6 & 8.5 \\
\hline
\end{tabular}

a Reaction conditions: nitro compound, $0.1 \mathrm{mmol}$; catalyst, $25 \mathrm{mg}$; hydrazine monohydrate, $1 \mathrm{mmol}$; Irradiation, White cold $20 \mathrm{~W}$ LED $\lambda>400 \mathrm{~nm}$, Power at reaction vessel $70 \mathrm{~W} / \mathrm{m}^{2}$; ${ }^{\mathrm{b}}$ Conversion (Conv.) was determined with gas chromatography (GC); ${ }^{\mathrm{c}}$ Isolated yield. 
The experiments were performed to probe the heterogeneous nature and reusability of the photocatalyst. After the completion of the reaction, the photocatalyst was recovered by centrifugation, washed with methanol and dried at $50{ }^{\circ} \mathrm{C}$. The recovered photocatalyst was reused for five subsequent runs under described experimental conditions. No significant loss was observed in the activity of the recycled catalyst, and the product yield remained almost unchanged even after five recycling experiments, which confirmed the true heterogeneous nature of the developed photocatalyst. Furthermore, an inductively coupled plasma-atomic emission spectrometry (ICP-AES) analysis of the photocatalyst after five recycling experiments showed a nickel content of $4.92 \mathrm{wt} \%$, which is nearly similar to that of a fresh catalyst $(4.98 \mathrm{wt} \%)$. These results confirmed that the developed photocatalyst was truly heterogeneous in nature and had not shown any detectable leaching during the reaction (Figure 9).

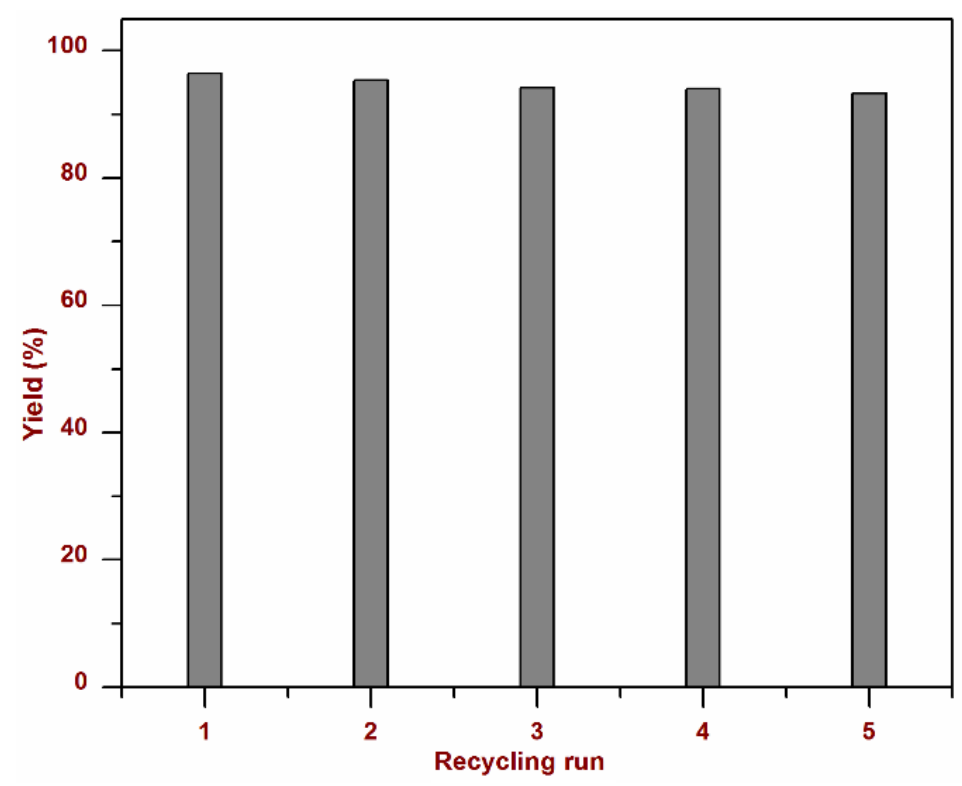

Figure 9. Results of recycling experiments.

Although the exact mechanism of the reaction is not clear at this stage, we assume that the generation of electron-hole pairs after the absorption of visible light is the first step to initiate the reaction [34]. Since the optical band gap of P-doped g- $\mathrm{PC}_{3} \mathrm{~N}_{4}$ is $1.52 \mathrm{eV}$, it can generate electrons and holes in its conduction and valence band, respectively. Electrons from the conduction band of P-doped carbon nitride get transferred to nickel nanoparticles due to lower Fermi level, which therefore work as electron sinks and capture the photogenerated electrons and prevent back charge recombination [35]. The electrons from NiNPs are transferred to nitrobenzene, which initiate a one electron reduction step [36]. The holes in the valence band of g- $\mathrm{PC}_{3} \mathrm{~N}_{4}$ oxidize hydrazine hydrate and generate electrons and protons along with nitrogen gas. The protons were used for the hydrogenation of activated molecules of nitrobenzene. As for the reduction of nitrobenezene to aniline, six protons and six electrons are required, so $3 / 2 \mathrm{NH}_{2} \mathrm{NH}_{2} \cdot \mathrm{H}_{2} \mathrm{O}$ mole were consumed per mole of reactant (Scheme 3). 


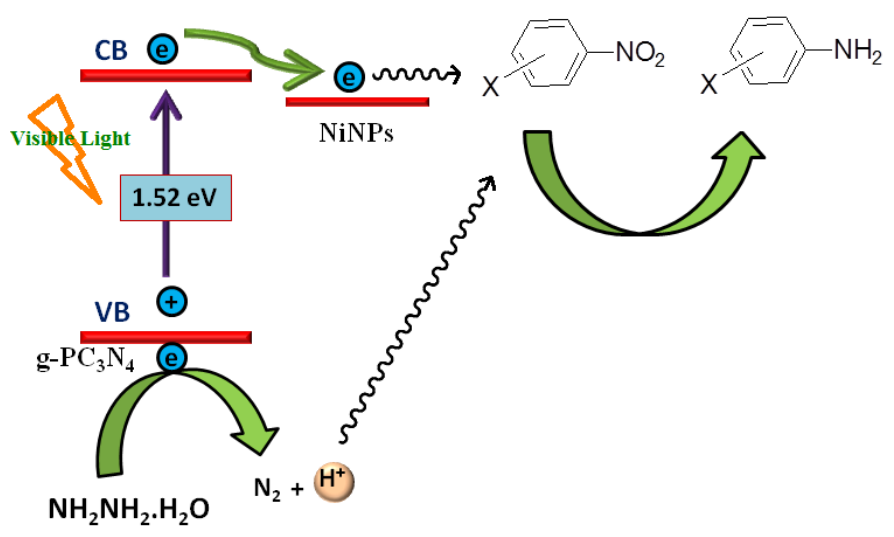

Scheme 3. Plausible mechanism on the basis of the band gap structure for the visible light reduction of nitrobenzenes by $\mathrm{Ni} @ \mathrm{~g}-\mathrm{PC}_{3} \mathrm{~N}_{4}$ photocatalyst. $\mathrm{CB}$ : conduction band; VB: valence band.

\section{Experimental Section}

\subsection{Materials}

Dicyandiamide (99\%), 1-butyl-3-methylimidazolium hexafluorophosphate $\left[\mathrm{BmimPF}_{6}\right](\geqslant 98.5 \%)$, nickel chloride hexahydrate $(\geqslant 98 \%)$, cetyltrimethylammonium bromide $(\geqslant 98 \%)$ and sodium borohydride $(\geqslant 98.0 \%)$ were purchased from Aldrich (St. Louis, MO, USA) and used as received. All substrates and solvents were purchased from Merck India Ltd (Mumbai, Maharashtra, India) and used without further purification.

\subsection{Characterizations}

The rough morphological surface properties of materials were determined with the help of scanning electron microscopy (SEM) using FE-SEM (Jeol Model JSM-6340F (Tokyo, Japan). For elaborating the fine structure of the catalysts, high-resolution transmission electron microscopy (HRTEM) was used and HRTEM images were collected on FEI-TecnaiG ${ }^{2}$ Twin TEM (Hillsboro, OR, USA) operating at an acceleration voltage of $200 \mathrm{kV}$. For sample preparation, a very dilute suspension of material was deposited on a carbon coated TEM grid. TEM images were processed on GATAN micrograph software (Munchen, Germany). The vibration spectra (FT-IR) of samples were recorded on a Perkin-Elmer spectrum RX-1 IR spectrophotometer (Waltham, MA, USA) using a potassium bromide window. X-ray diffraction patterns for determining the phase structure and crystalline properties of the materials were obtained on a Bruker D8 Advance diffractometer (Billerica, MA, USA) working at $40 \mathrm{kV}$ and $40 \mathrm{~mA}$ with $\mathrm{Cu} \mathrm{K} \mathrm{K}_{\alpha}$ radiation $(\lambda=0.15418 \mathrm{~nm})$. Nitrogen adsorption-desorption isotherms for calculating surface properties like Brunauer-Emmet-Teller surface area $\left(S_{\mathrm{BET}}\right)$, Barret-Joiner-Halenda (BJH) porosity, pore volume, etc., were acquired on a $V_{\mathrm{P}}$. Micromeritics ASAP2010 (Norcross, GA, USA) at $77 \mathrm{~K}$. UV-Vis absorption spectra of solid samples were collected on a Perkin Elmer lambda-19 UV-VIS-NIR spectrophotometer (Waltham, MA, USA) by making $1 \mathrm{~mm}$ thick pellets using $\mathrm{BaSO}_{4}$ as reference. To check the thermal stability of materials, thermogravimetric analysis (TGA) was performed by using a TA-SDT Q-600 thermal analyser (Champaign, IL, USA) in the temperature range of 45 to $80{ }^{\circ} \mathrm{C}$ under nitrogen flow with a heating rate of $10^{\circ} \mathrm{C} / \mathrm{min}$. To determine the nickel content in the synthesized composites, ICP-AES analysis was performed by using inductively coupled plasma atomic emission spectrometer (ICP-AES, DRE, PS-3000UV, Leeman Labs Inc., Hudson, NH, USA). Samples for ICP-AES were made by digesting a calculated amount of samples with nitric acid followed by filtration and making volume up to $10 \mathrm{~mL}$ by adding deionized water. 


\subsection{Synthesis of Nickel Nanoparticles [26]}

Nickel nanoparticles were synthesized by following a literature procedure. In brief, to an aqueous suspension of nickel chloride hexahydrate $(0.152 \mathrm{mmol}, 0.019 \mathrm{~g})$ and cetyltrimethyl ammonium bromide, CTAB $(0.288 \mathrm{mmol}, 0.105 \mathrm{~g})$, an aqueous solution $(1.5 \mathrm{~mL})$ of $\mathrm{NaBH}_{4}(0.020 \mathrm{~g}, 0.526 \mathrm{mmol})$ was added dropwise. The mixture was vigorously stirred to obtain a black suspension. The particles were separated by centrifugation and washed with water several times.

\subsection{Synthesis of Phosphorous-Doped Graphitic Carbon Nitride $\left(g-P C_{3} N_{4}\right)[19,27]$}

Phosphorous-doped graphitic carbon nitride was synthesized by using $\mathrm{BmimPF}_{4}$ as a source of phosphorous. The phosphorous containing ionic liquid, $\mathrm{BmimPF}_{4}(0.5 \mathrm{~g})$ was dissolved in water $(6 \mathrm{~mL})$ and stirred for $5 \mathrm{~min}$. After that, dicyandiamide $(1 \mathrm{~g})$ was added to this solution and the mixture was heated at $100{ }^{\circ} \mathrm{C}$ until all the water had completely evaporated, which resulted in the formation of a white solid. The obtained solid was subjected to heating at a programmed temperature. Firstly the sample was heated up to $350^{\circ} \mathrm{C}$ within $2 \mathrm{~h}$, then the temperature was maintained at a constant for the next $4 \mathrm{~h}$. The temperature was then raised to $550{ }^{\circ} \mathrm{C}$ in $1 \mathrm{~h}$ and then this temperature was maintained at a constant for the next $4 \mathrm{~h}$. The sample was collected at room temperature.

\subsection{Synthesis of Nickel Nanoparticles Decorated on Phosphorous-Doped Graphitic Carbon Nitride (Ni@g-PC $\left.C_{3} N_{4}\right)$}

For the synthesis of nickel nanoparticle-decorated carbon nitride, nickel particles were added along with $\mathrm{BmimPF}_{4}$ and dicyandiamide during the synthesis step. Then the sample was heated at a programmed temperature as in the synthesis of P-doped carbon nitride.

\subsection{Photocatalytic Reduction Experiment}

To check the activity of the catalyst for the visible light mediated reduction, a 20 watt LED (Model No. HP-FL-20W-F-Hope LED Opto-Electric Co., Ltd (Shenzhen, China), $\lambda>400 \mathrm{~nm}$ ) was used as a source of visible light. A round bottom flask was charged with $25 \mathrm{mg}$ of $5 \% \mathrm{Ni} @ g-\mathrm{PC}_{3} \mathrm{~N}_{4}$ catalyst, $0.1 \mathrm{mmol}$ of nitrobenzene and $1.0 \mathrm{mmol}$ of hydrazine monohydrate in $10 \mathrm{~mL}$ solvent mixture of acetonitrile/DCM/methanol. After sonication for $10 \mathrm{~min}$, the resulting mixture was irradiated under visible light. To monitor the progress of the reaction, the sample was withdrawn at a certain period of time and analyzed by gas chromatography-flame ionization detector (GC-FID). After the completion of the reaction, the solvent was removed by rotary evaporation and the product was isolated using column chromatography. The identification of product was done by gas chromatography-mass spectrometry (GC-MS) and ${ }^{1} \mathrm{H}$-nuclear magnetic resonance $\left({ }^{1} \mathrm{H}-\mathrm{NMR}\right)$.

\section{Conclusions}

We have synthesized a novel, highly efficient and visible light-active nickel nanoparticlesdecorated P-doped carbon nitride for the selective hydrogenation of nitro compounds to the corresponding amines in the presence of hydrazine monohydrate as a proton donor. Due to P-doping, the developed photocatalyst absorbs the maximum part of the visible region and nickel nanoparticles work as an electron trap. The developed photocatalyst was found to be highly effective and afforded excellent product yields within $8-10.5 \mathrm{~h}$ at ambient temperature under visible light irradiation. Due to the heterogeneous nature of photocatalyst, it can be easily recovered and reused for further reactions without any significant decrease in its activity. The enhanced performance of the catalyst in the visible region can be explained on the basis of reduced band gap, which generates electron-hole pairs through the absorption of visible light. Photogenerated electrons are efficiently captured by nickel nanoparticles on the sheets and subsequently transferred to substrate molecule, while holes are used to oxidize hydrazine hydrate and extract required protons and electrons for the reaction.

Acknowledgments: Authors are thankful to Director IIP for granting permission to publish these results. Anurag Kumar and Pawan Kumar are thankful to Council of Scientific and Industrial Research (CSIR) New Delhi 
for providing research fellowships. Chetan Joshi kindly acknowledges CSIR, New Delhi for providing technical Human Resource (H.R.) under XII five year projects. Manvi Manchanda acknowledges Department of Science and Technology (DST) New Delhi, for providing fellowship under the Women Societal B (WoS-B) program. Analytical department is kindly acknowledged for the analysis of samples. Rabah Boukherroub acknowledges financial support from the Centre National de la Recherche Scientifique (CNRS), Lille1 University and Nord Pas de Calais region.

Author Contributions: Anurag Kumar, Pawan Kumar, Chetan Joshi and Manvi Manchanda were involved in the synthesis, characterization and catalytic evaluation of photocatalyst. Suman L. Jain and Rabah Boukherroub helped in the technical discussion, interpretation of data and writing of the manuscript.

Conflicts of Interest: The authors declare no conflict of interest.

\section{References}

1. Narayanam, J.M.R.; Stephenson, C.R.J. Visible light photoredox catalysis: Applications in organic synthesis. Chem. Soc. Rev. 2011, 40, 102-113. [CrossRef] [PubMed]

2. Yoon, T.P.; Ischay, M.A.; Du, J. Visible light photocatalysis as a greener approach to photochemical synthesis. Nat. Chem. 2010, 2, 527-532. [CrossRef] [PubMed]

3. Lang, X.; Chen, X.; Zhao, J. Heterogeneous visible light photocatalysis for selective organic transformations. Chem. Soc. Rev. 2014, 43, 473-486. [CrossRef] [PubMed]

4. Su, F.; Mathew, S.C.; Lipner, G.; Fu, X.; Antonietti, M.; Blechert, S.; Wang, X. mpg- $\mathrm{C}_{3} \mathrm{~N}_{4}$-Catalyzed Selective Oxidation of Alcohols Using $\mathrm{O}_{2}$ and Visible Light. J. Am. Chem. Soc. 2010, 132, 16299-16301. [CrossRef] [PubMed]

5. Wang, A.J.; Cheng, H.Y.; Liang, B.; Ren, N.Q.; Cui, D.; Lin, N.; Kim, B.H.; Rabaey, K. Efficient reduction of nitrobenzene to aniline with a biocatalyzed cathode. Environ. Sci. Technol. 2011, 45, 10186-10193. [CrossRef] [PubMed]

6. Corma, A.; Concepcion, P.; Serna, P. A different reaction pathway for the reduction of aromatic nitro compounds on gold catalysts. Angew. Chem. Int. Ed. 2007, 46, 7266-7269. [CrossRef] [PubMed]

7. Wang, J.; Yuan, Z.; Nie, R.; Hou, Z.; Zheng, X. Hydrogenation of nitrobenzene to aniline over silica gel supported nickel catalysts. Ind. Eng. Chem. Res. 2010, 49, 4664-4669. [CrossRef]

8. Kulkarni, A.S.; Jayaram, R.V. Liquid phase catalytic transfer hydrogenation of aromatic nitro compounds on perovskites prepared by microwave irradiation. Appl. Catal. A 2013, 252, 225-230. [CrossRef]

9. Xu, W.Y.; Gao, T.Y.; Fan, J.H. Reduction of nitrobenzene by the catalyzed Fe-Cu process. J. Hazard. Mater. 2005, 123, 232-241. [CrossRef] [PubMed]

10. Agrawal, A.; Tratnyek, P.G. Reduction of Nitro Aromatic Compounds by Zero-Valent Iron Metal. Environ. Sci. Technol. 1995, 30, 153-160. [CrossRef]

11. Tanaka, A.; Nishino, Y.; Sakaguchi, S.; Yoshikawa, T.; Imamura, K.; Hashimoto, K.; Kominami, H. Functionalization of a plasmonic $\mathrm{Au} / \mathrm{TiO}_{2}$ photocatalyst with an $\mathrm{Ag}$ co-catalyst for quantitative reduction of nitrobenzene to aniline in 2-propanol suspensions under irradiation of visible light. Chem. Commun. 2013, 49, 2551-2553. [CrossRef] [PubMed]

12. Füldner, S.; Pohla, P.; Bartling, H.; Dankesreiter, S.; Stadler, R.; Gruber, M.; Pfitzner, A.; König, B. Selective photocatalytic reductions of nitrobenzene derivatives using $\mathrm{PbBiO}_{2} X$ and blue light. Green Chem. 2011, 13, 640-643. [CrossRef]

13. Richner, G.; Bokhoven, J.A.; van Neuhold, Y.M.; Makosch, M.; Hungerbühler, K. In situ infrared monitoring of the solid/liquid catalyst interface during the three-phase hydrogenation of nitrobenzene over nanosized $\mathrm{Au}$ on $\mathrm{TiO}_{2}$. Phys. Chem. Chem. Phys. 2011, 13, 12463-12471. [CrossRef] [PubMed]

14. Huang, H.; Zhou, J.; Liu, H.; Zhou, Y.; Feng, Y. Selective photoreduction of nitrobenzene to aniline on $\mathrm{TiO}_{2}$ nanoparticles modified with amino acid. J. Hazard. Mater. 2010, 178, 994-998. [CrossRef] [PubMed]

15. Wang, X.; Maeda, K.; Chen, X.; Takanabe, K.; Domen, K.; Hou, Y.; Fu, X.; Antonietti, M. Polymer semiconductors for artificial photosynthesis: Hydrogen evolution by mesoporous graphitic carbon nitride with visible light. J. Am. Chem. Soc. 2009, 131, 1680-1681. [CrossRef] [PubMed]

16. Wang, X.; Blechert, S.; Antonietti, M. Polymeric graphitic carbon nitride for heterogeneous photocatalysis. ACS Catal. 2012, 2, 1596-1606. [CrossRef]

17. Cui, Y.; Huang, J.; Fu, X.; Wang, X. Metal-free photocatalytic degradation of 4-chlorophenol in water by mesoporous carbon nitride semiconductors. Catal. Sci. Technol. 2012, 2, 1396-1402. [CrossRef] 
18. Yan, S.C.; Li, Z.S.; Zou, Z.G. Photodegradation performance of $\mathrm{g}-\mathrm{C}_{3} \mathrm{~N}_{4}$ fabricated by directly heating melamine. Langmuir 2009, 25, 10397-10401. [CrossRef] [PubMed]

19. Zhang, Y.; Mori, T.; Ye, J.; Antonietti, M. Phosphorus-doped carbon nitride solid: enhanced electrical conductivity and photocurrent generation. J. Am. Chem. Soc. 2010, 132, 6294-6295. [CrossRef] [PubMed]

20. Hong, J.; Xia, X.; Wang, Y.; Xu, R. Mesoporous carbon nitride with in situ sulfur doping for enhanced photocatalytic hydrogen evolution from water under visible light. J. Mater. Chem. 2012, 22. [CrossRef]

21. Wang, Y.; Di, Y.; Antonietti, M.; Li, H.; Chen, X.; Wang, X. Excellent visible-light photocatalysis of fluorinated polymeric carbon nitride solids. Chem. Mater. 2010, 22, 5119-5121. [CrossRef]

22. Kumar, A.; Kumar, P.; Joshi, C.; Ponnada, S.; Pathak, A.K.; Ali, A.; Sreedhar, B.; Jain, S.L. A [Fe(bpy) $)_{3}^{2+}$ grafted graphitic carbon nitride hybrid for visible light assisted oxidative coupling of benzylamines under mild reaction conditions. Green Chem. 2016. [CrossRef]

23. Kumar, S.; Kumar, P.; Deb, A.; Maiti, D.; Jain, S.L. Graphene oxide grafted with iridium complex as a superior heterogeneous catalyst for chemical fixation of carbon dioxide to dimethylformamide. Carbon 2016, 100, 632-640. [CrossRef]

24. Kumar, P.; Bansiwal, A.; Labhsetwar, N.; Jain, S.L. Visible light assisted photocatalytic reduction of $\mathrm{CO}_{2}$ using a graphene oxide supported heteroleptic ruthenium complex. Green Chem. 2015, 17, 1605-1609. [CrossRef]

25. Gusain, R.; Kumar, P.; Sharma, O.P.; Jain, S.L.; Khatri, O.P. Reduced graphene oxide-CuO nanocomposites for photocatalytic conversion of $\mathrm{CO}_{2}$ into methanol under visible light irradiation. Appl. Catal. B 2016, 181, 352-362. [CrossRef]

26. Singh, S.K.; Xu, Q. Bimetallic Ni-Pt Nanocatalysts for selective decomposition of hydrazine in aqueous solution to hydrogen at room temperature for chemical hydrogen storage. Inorg. Chem. 2010, 49, 6148-6152. [CrossRef] [PubMed]

27. Wang, Y.; Zhang, J.; Wang, X.; Antonietti, M.; Li, H. Boron-and fluorine-containing mesoporous carbon nitride polymers: Metal-free catalysts for cyclohexane oxidation. Angew. Chem. Int. Ed. 2010, 49, 3356-3359. [CrossRef] [PubMed]

28. Chen, D.H.; Wu, S.H. Synthesis of nickel nanoparticles in water-in-oil microemulsions. Chem. Mater. 2000, 12, 1354-1360. [CrossRef]

29. Liu, J.; Zhang, T.; Wang, Z.; Dawson, G.; Chen, W. Simple pyrolysis of urea into graphitic carbon nitride with recyclable adsorption and photocatalytic activity. J. Mater. Chem. 2011, 21, 14398-14401. [CrossRef]

30. Ge, L. Synthesis and photocatalytic performance of novel metal-free $\mathrm{g}-\mathrm{C}_{3} \mathrm{~N}_{4}$ photocatalysts. Mater. Lett. 2011, 65, 2652-2654. [CrossRef]

31. Rouquerol, J.; Avnir, D.; Fairbridge, C.W.; Everett, D.H.; Haynes, J.M.; Pernicone, N.; Ramsay, J.D.F.; Sing, K.S.W.; Unger, K.K. Recommendations for the characterization of porous solids (Technical Report). Pure Appl. Chem. 1994, 66, 1739-1758. [CrossRef]

32. Wang, Y.; Wang, X.; Antonietti, M. Polymeric graphitic carbon nitride as a heterogeneous organocatalyst: from photochemistry to multipurpose catalysis to sustainable chemistry. Angew. Chem. Int. Ed. 2012, 51, 68-89. [CrossRef] [PubMed]

33. Su, J.; Geng, P.; Li, X.; Zhao, Q.; Quan, X.; Chen, G. Novel phosphorus doped carbon nitride modified $\mathrm{TiO}_{2}$ nanotube arrays with improved photoelectrochemical performance. Nanoscale 2015, 7, 16282-16289. [CrossRef] [PubMed]

34. Ran, J.; Ma, T.Y.; Gao, G.; Du, X.Y.; Qiao, S.Z. Porous P-doped graphitic carbon nitride nanosheets for synergistically enhanced visible-light photocatalytic $\mathrm{H}_{2}$ production. Energy Environ. Sci. 2015, 8, 3708-3717. [CrossRef]

35. Datta, K.K.R.; Reddy, B.V.S.; Ariga, K.; Vinu, A. Gold nanoparticles embedded in a mesoporous carbon nitride stabilizer for highly efficient three-component coupling reaction. Angew. Chem. Int. Ed. 2010, 49, 5961-5965. [CrossRef] [PubMed]

36. Yuliati, L.; Yang, J.H.; Wang, X.; Maeda, K.; Takata, T.; Antonietti, M.; Domen, K. Highly active tantalum (v) nitride nanoparticles prepared from a mesoporous carbon nitride template for photocatalytic hydrogen evolution under visible light irradiation. J. Mater. Chem. 2010, 20, 4295-4298. [CrossRef]

(C) 2016 by the authors; licensee MDPI, Basel, Switzerland. This article is an open access article distributed under the terms and conditions of the Creative Commons by Attribution (CC-BY) license (http://creativecommons.org/licenses/by/4.0/). 